\title{
Sensitivity of design parameters on energy, system and comfort performances for radiant cooled office buildings in the tropics
}

\author{
Riccardo Talami ${ }^{1}$ and J. Alstan Jakubiec ${ }^{2}$ \\ ${ }^{1}$ School of Architecture, Building and Civil Engineering, Loughborough University, \\ Loughborough, United Kingdom \\ ${ }^{2}$ Daniels Faculty of Architecture, Landscape, and Design, University of Toronto, Toronto, Canada
}

\begin{abstract}
The research community has worked on optimizing the design, performance, and operation of radiant system technologies; however, the holistic interactions between architectural design decisions and radiant cooling systems design in the tropics have been left unexplored. Morris sensitivity analysis is used to analyze the design performance impact, interactions, variability and nonlinear effects of 13 building and systems design parameters on energy, system and comfort performances for 3 radiant systems typologies applied to a parametric office building in the tropical climate of Singapore. It is found that window solar heat gain coefficient, windowto-wall ratio, and system set-point temperature play a key role to ensure building's high multi-objective performance and have an almost monotonic behavior with respective values falling below or equal to $54 \%$ and $57 \%$ and high room dry bulb air temperatures between $24.8^{\circ} \mathrm{C}$ and $27^{\circ} \mathrm{C}$.
\end{abstract}

\section{Introduction}

Achieving a thermally comfortable environment while reducing the energy consumption in buildings has become a necessity in the tropical hot and humid climate, where sensible and latent cooling represents the largest portion of the energy expenditure. In Singapore, the building sector accounts for $31 \%$ of the total energy consumed in the country (Chua et al., 2013), and around $60 \%$ is used for cooling and ventilation needs (Lee et al., 2004). With the demand for space cooling expected to triple between 2010 and 2050, the priority for countries with hot and humid climates should be the design of high-performing building fabrics combined with the wide adoption of lowenergy and cost-effective cooling systems. Such designs should reduce space peak loads, cooling needs and electricity demand resulting in improved energy efficiency and system performances while maintaining acceptable thermal comfort levels.

Although building performance simulations (BPS) are key analyses in this effort, they are widely carried out later in the design process when most of the decisions affecting occupant's thermal comfort, energy \& system performance and costs have already been made (Lohnert et al., 2003), leaving possible design alternatives unexplored and therefore considered inefficient to support the decision-making process in the design of highperforming building. However, the consideration of uncertainties in the design scenario-multiple variations and possibilities during the design process-could improve and enable design decision support, particularly if augmented by sensitivity analysis (SA), defined as the quantitative measure of the impact of variables on predefined outputs (Saltelli et al., 2004). The early-design process supported with the use of decision-making methodologies, BPS, and SA has the potential to enhance design solutions by providing knowledge of interactions and dependencies between building performance metrics and active \& passive design parameters; therefore, insights into the consequences and robustness of individual design decisions are gained and the trade-offs between conflicting design goals are identified, avoiding thus time-consuming and expensive last-minute design changes.

The interaction between building fabric and HVAC systems play a key role from the beginning of the design process when installing radiant cooling systems, defined as sensible cooling system that meets more than $50 \%$ of total space cooling load through thermal radiation. Thermal energy radiates from the heat loads present in the space (objects, people, equipment and lights) to the surfaces, cooled by circulating a high-temperature fluid through pipes embedded in the structure of the building (TABS-Thermally Active Building Systems), in a layer of screed or insulation (ESS-Embedded Surface Systems) or hung from the ceiling (RCP-Radiant Ceiling Panels) (ASHRAE, 2016; Babiak et al., 2009). Radiant system operational temperatures are close to the room temperature; therefore, their cooling capacity is lower than a conventional cooling system, and it is fundamental to design a high-performing building fabric to reduce external heat gains to keep the zone sensible load lower than the system cooling capacity. Radiant cooling systems provide an opportunity to achieve significant energy savings, take up less space than all-air systems, reduce peak loads, and are quiet in their operation (Olesen, 2012). With a proper design, equal or improved thermal comfort levels compared to conventional all-air systems can be achieved (Karmann et al., 2017) and application of these systems has increased in recent years (Talami et al., 2017).

Given the strong influence that architectural design has on radiant systems design, it is fundamental to consider their installation from the beginning of the design, integrated and balanced with the proposed formal design features, exploring how conceptual design phases will influence the load balance of the building and the operation and 
effectiveness of radiant cooling systems. In fact, early design stages offer the greatest potential for creating a high-quality and sustainable design that results in a low energy building working towards a wide-variety of defined environmental goals. The lack of design detail early in a project is both an analytical limitation and an opportunity to identify emergent design solutions.

This research aims to support early-design decisions and simplify the design scenario when integrating radiant cooling systems in the architectural design related to energy consumption, thermal comfort and system operation in the tropics using a sensitivity analysis approach. This manuscript (1) addresses the holistic design of effective radiant cooling systems and the architectural environments that they serve, (2) identifies variables that have high impacts on the performance indicators, negligible parameters while also underlying their interactions and non-linear effects, and (3) proposes preliminary design indications of the parameters values to adopt when integrating radiant cooling systems and the building fabric to achieve high multi-objective goals.

\section{Methodology}

Figure 1 depicts the workflow implemented in its essential passages.

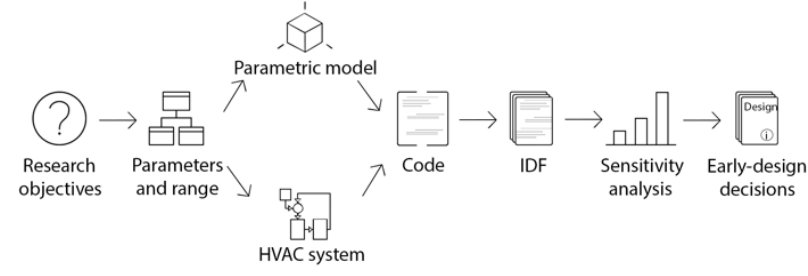

Figure 1: Workflow diagram.

The authors focused on 3 building performance metrics: (1) the total cooling energy consumption expressed as the Energy Use Intensity (EUI, $\mathrm{kWh} / \mathrm{m}^{2}$ ) of $\mathrm{HVAC}$ components (DOAS-Dedicated Outdoor Air System, cooling tower and the two separate chillers for sensible and latent cooling needs), (2) the occupant's thermal comfort (hours) expressed as the frequency with which occupants would feel uncomfortable in one or more occupied zones, and (3) the system's operational effectiveness as the zone weighted incremental difference in number of hours when the zone temperature is above the cooling set-point (weighted hours).

The target is to minimize energy consumption while maintaining an acceptable thermal comfort level and system operation by adopting a complimentary set of design variables. Therefore, the authors decided to fix parameters related to internal loads, equipment \& occupancy schedule, and most of the mechanical components of the system to better investigate the variable parameters related to building fabric and system operation. Moreover, the present study focuses in the context of Singapore, and the results will be specific under the design limitations of a tropical climate. The approach illustrated herein can be extended to different climatic locations, building typologies, urban overshadowing conditions and energy systems. The parameters selected to test in the sensitivity analysis are classified into 5 main categories: building, façade, thermal mass, operational strategy, and system type. Beyond common architectural parameters, three radiant system distribution types were tested with varying thermostat set point temperatures and supply temperatures of the HVAC plant for cooling. The authors opted to use a classification scheme based on current standards, reviewing the ASHRAE Handbook (2016), and the REHVA guidebook (Babiak et al., 2009). Based on these guidelines and categorized according to their response time (Ning et al., 2017) three different types are identified: (1) radiant ceiling panels (RCP) which offer a quick response time $(1.8-6.5$ minutes $)$ since the pipes are attached to thin conductive metal panels fixed to the ceiling structure, (2) embedded surface systems (ESS) characterized by pipes embedded within the surface layer and insulated from the ceiling structure with a medium response time (0.8 - 8.7 hours), and (3) thermally activated building systems (TABS) where the pipes are thermally coupled and embedded in the central core of the ceiling structure exploiting the thermal mass potential of the massive concrete layer with, consequently, a slow response time in the range of $8.7-18.8$ hours. Figure 2 displays the assembly construction of RCP (left), ESS (centre) and TABS (right).

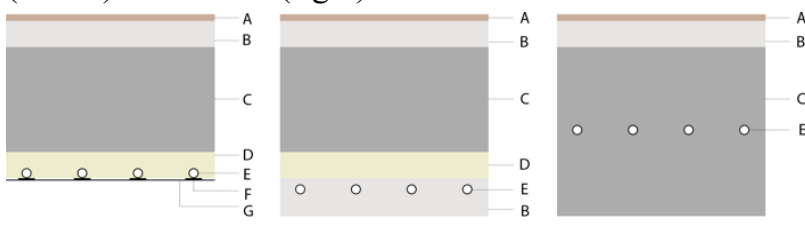

A $=$ Floor covering - PVC. $\quad \mathbf{D}=$ Insulating layer $-X P S$ board $5 \mathrm{~cm} . \quad \mathbf{G}=$ Metal steel panel $-3 \mathrm{~mm}$. B $=$ Floor construction - Concrete screed $5 \mathrm{~cm}$. E $=$ Cooling pipes $(1.5 \mathrm{~cm}$ diameter, $15 \mathrm{~cm}$ spacing $)$ C = Building structural slab - Lightweight concrete (parametric). $\mathbf{F}=$ Conductive device.

Figure 2: Assembly construction of RCP, ESS and TABS.

The authors selected the perturbation values of each parameter from common engineering \& design practice guidebooks and based on current energy legislations, stressing the range of variability for some parameters to further analyse their reactions. The selected parameters are: building aspect ratio, orientation, number of floors and floor-to-floor height, façade U-value, window-to-wall ratio and shade length, window U-value and solar heat gain coefficient, incremental thermal mass and slab thickness, system set-point temperature and supply liquid temperature. The incremental thermal mass parameter is defined in $\mathrm{kg}$ of concrete per $\mathrm{m}^{2}$ of zone area and it includes structure, columns and interior walls as a proxy to represent lightweight and heavyweight structures. The slab thickness parameter allows to control the thickness to define the amount of thermal mass (concrete or screed) that the radiant system can exploit for its operation, but it is not applied to RCP models. Consequently, it regulates the roof and internal floors U-values.

A building energy simulation model of a generic openplan office floor is designed using Grasshopper ${ }^{\mathrm{TM}}$ for Rhinoceros ${ }^{\mathrm{TM}}$ and its features are defined using Archsim plug-in (Dogan, 2013). The top zone ceiling surface were always modelled as highly insulated in order to avoid influencing the model sensitivity results. The occupied space is divided into five thermal zones. Specific basic 


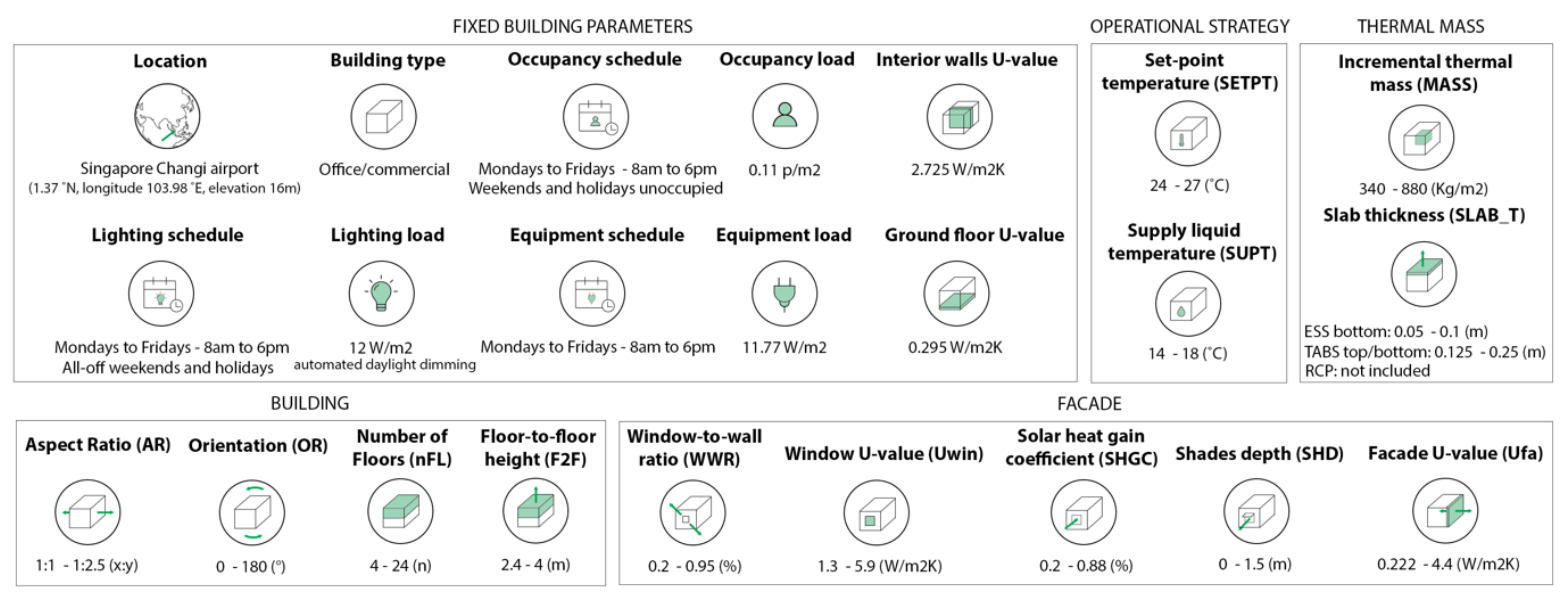

Figure 3: Baseline and parametric inputs with relative perturbations.

building features relating to internal loads and occupancy have been chosen based on the norms for office buildings in Singapore and are kept fixed throughout the study. Figure 3 details the input parameters with their maximum and minimum perturbation values and the fixed building features.

The HVAC system has been designed using the EnergyPlus $^{\mathrm{TM}}$ simulation platform (Design Builder interface). In a conventional air-based space conditioning sensible and latent cooling are combined, representing an energy-demanding process and a reason for the frequent issue of overcooling. The adoption of radiant cooling systems coupled with a DOAS in buildings allows the separation of sensible and latent cooling by decoupling the load using two chillers - one chiller provides higher temperatures $\left(14-18{ }^{\circ} \mathrm{C}\right)$ for sensible cooling to maintain the interior temperature control at $24-27{ }^{\circ} \mathrm{C}$ and the second one handles mainly the latent cooling load, requiring $6-8^{\circ} \mathrm{C}$ to dehumidify the interior air to maintain acceptable thermal comfort levels (Jeong and Mumma, 2006). This approach reduces the electricity consumption as the sensible chiller produces higher temperatures with a decreased temperature lift, and the latent chiller \& DOAS work to dehumidify the minimally required volume of air for ventilation delivering it to the zones without reheat, controlling the humidity and offsetting some sensible load fraction as well. Additionally, this operational strategy allows a smaller sized unit and components (compressor, fans) and the reduction of the HVAC energy consumption. Moreover, the adoption of a DOAS for dehumidification and ventilation purposes sets aside the fear of condensation on radiant panels in the tropics. Figure 4 depicts the modelled radiant cooling setup which comprises the radiant ceiling in the conditioned space in which chilled water is delivered from a combined cooling tower \& electric chiller operation and a DOAS with constant volume fans and a separate electric chiller aided with the cooling tower. The DOAS accommodates $\sim 36 \%$ of the space sensible load and the radiant cooling system covers the remaining load ( $\sim 64 \%$ ) to ensure the balance and indoor thermal comfort. After calibrating the system, a script allowed interoperability between simple 'ideal air loads'

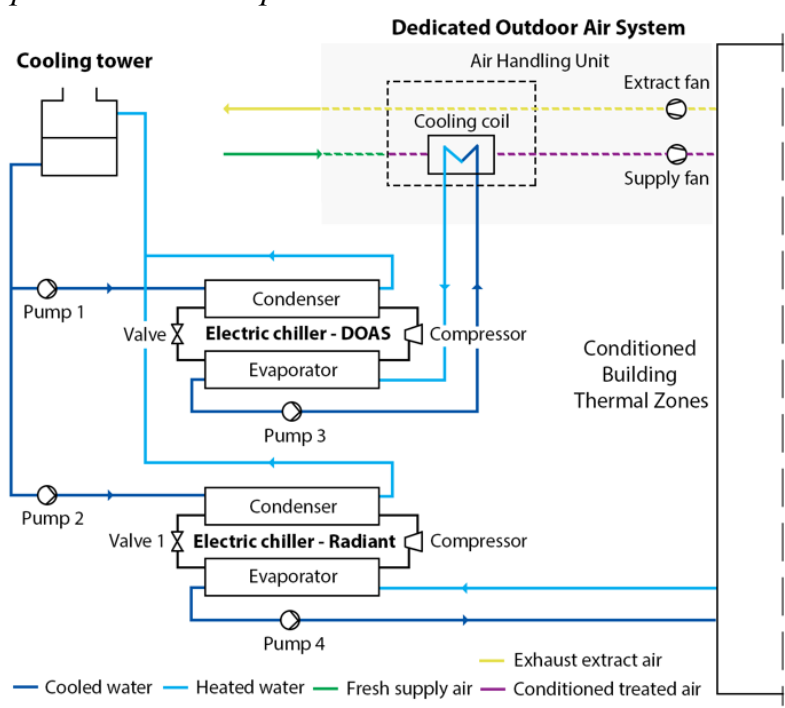

Figure 4: Schematic of the radiant cooling setup

simulation files generated by Archsim which report only the building loads and EnergyPlus. HVAC information was added to the simple EnergyPlus Input Data Files (IDF's) via the aforementioned script, which added all systems components detailed in Figure 4 to the files as well as removed the 'ideal air loads' portions of the IDF.

For this study, the authors adopted the enhanced Morris's sensitivity method (Campolongo et al., 2007) since it is considered a reliable one-factor-at-a-time (OAT) screening method combined with a redifined factorial sampling strategy enabling a better exploration of the input space among a large number of input parameters, relatively minimizing the number of samples. The Morris method has been widely used in the field of building energy analysis (Tian, 2013) and estimates the elementary effect (EE), defined as the relative magnitude of change of each input parameter using a OAT evenly distributed sampling process on the output along a sequence of points (trajectory) in which one point represents a single evaluation run. The method generates a random starting point for each defined trajectory in the input space and moving one factor at a time in a random order computes the EE between the two simulation runs where the input factor is modified. The EE is defined as the following in Equation 1: 


$$
E E_{i}(x)=\frac{\left[y\left(x_{1}, \ldots, x_{i-1}, x_{i}+\Delta, x_{i+1}, \ldots, x_{n}\right)-y(x)\right]}{\Delta}
$$

The sensitivity of each design parameter is evaluated by two measure indicators: the mean value of the distribution of absolute $\mathrm{EE}\left(\mu^{*}\right)$ which estimates the main effect of the input factor on the output, indicating an input parameter with an important overall influence on the output and parameters whose effect can be considered negligible (Equation 2), and the standard deviation $(\sigma)$ which estimates the factor's higher order effects through the assessment of the interaction with other factors or whose effect is non-linear (Equation 3).

$$
\begin{gathered}
\mu^{*}=\frac{1}{r} \sum_{i=1}^{r}\left|E E_{i}\right| \\
\sigma=\sqrt{\frac{1}{(r-1)} \sum_{i=1}^{r}\left|E E_{i}-\mu\right|^{2}}
\end{gathered}
$$

The sampling of the parameters was done parametrically via Grasshopper resulting in EnergyPlus simulation models with radiant cooling systems in place and a wide variety of parameter changes as described in Figure 3. 200 is used as the number of resampling trajectories to ensure the reliability of the results (Menberg et al., 2016) leading to a total number of 8,200 runs according to Equation 4:

$$
n=r(k+1)
$$

where $n$ is the number of final samples, $r$ is the number of simulation trajectories, and $k$ is the number of input variables for which elementary effects are assessed. After all the 8,200 combinations have been simulated $(2,800$ for TABS and ESS and 2,600 for RCP), the resulting outputs are imported into SALib module (Herman and Usher, 2017) in Python and used to calculate $\mu^{*}$ and $\sigma$.

\section{Results}

The distribution of results for each performance metric and system type are displayed in Figure 5. It is found that all 3 system typologies (TABS, ESS and RCP), if coupled with design strategies aimed to reduce the external gains and latent loads, allow acceptable thermal comfort levels, system's operation and reduced energy consumption, as shown from the lower whiskers of each boxplot. The boxplots portray how ceiling panels represent the best solution for the tropical climate of Singapore due to their fast response time and assembly configuration. Night time or early morning operation of TABS can overcome its slow response time by storing the energy and releasing it during the day, shifting part of the building loads. It is also noteworthy to point out that the median value of the Cooling EUI results of the three distribution systems falls below the representative whole-building energy-model value for cooling consumption of a large office building with minimum local green rating in the tropics (62.8 $\mathrm{kWh} / \mathrm{m}^{\wedge} 2$-yr) estimated by Duarte et al. (2017), showing the benefit of the implementation of radiant cooling technologies in Singapore.

The analysis of the EE obtained through Morris sensitivity analysis varies in the strengths and range of their effects, and the ranked parameter importance changes across the 3 different system typologies and evaluation types. The overall sensitivity ranking and elementary effects scatter plots for cooling EUI, uncomfortable and unmet hours are presented in Figure 6. The error bars indicate the confidence interval of $\mu^{*}$ values in the metric output unit. Based on the ratio $\sigma / \mu^{*}$, the higher-order effects are portrayed according to a classification scheme proposed by Garcia Sanchez et al. (2014). The parameters displayed below the line $\sigma / \mu^{*}=$ 0.1 are considered as having an almost linear relationship with the results while, if they are located above the line $\sigma$ $/ \mu^{*}=1$, they are characterized by a high nonlinear relationship with the results and non-monotonic behaviour, showing that there might be an interaction with other input factors. Moreover, if the parameters appear between the lines $\sigma / \mu^{*}=0.1$ and $\sigma / \mu^{*}=0.5$ they have a monotonic behaviour while, if they are between the lines $\sigma / \mu^{*}=0.5$ and $\sigma / \mu^{*}=1$, they are almost-monotonic. The $\sigma / \mu^{*}$ charts prove the negligibility of the parameters characterized by low $\mu^{*}$ values when they show low standard deviation $(\sigma)$ values as well.

\section{TABS results}

In this section the results for the Thermally Active Building Systems (TABS) distribution type will be discussed. When assessing sensitivity on thermal comfort, the parameters with the highest $\mu^{*}$ values are, in this order: the window solar heat gain coefficient, the façade window-to-wall-ratio, and the system set point temperature. A subsequent group of parameters with lower impact but significant influence includes the building floor-to-floor height followed by the façade shades length, the system supply temperature, the window $\mathrm{U}$-value, the building aspect ratio and the façade U-value. The remaining parameters (building slab thickness, number of floors, orientation and incremental thermal mass) can be classified as negligible. The system set point temperature and its variability might interact with most of the second group of influential parameters since they are all characterized by a non-linear effects, non-monotonic behaviour or interactions. The other dominating inputs and the building floor-to-floor ratio from the second group exhibit an almost monotonic behaviour and high $\sigma$ values.
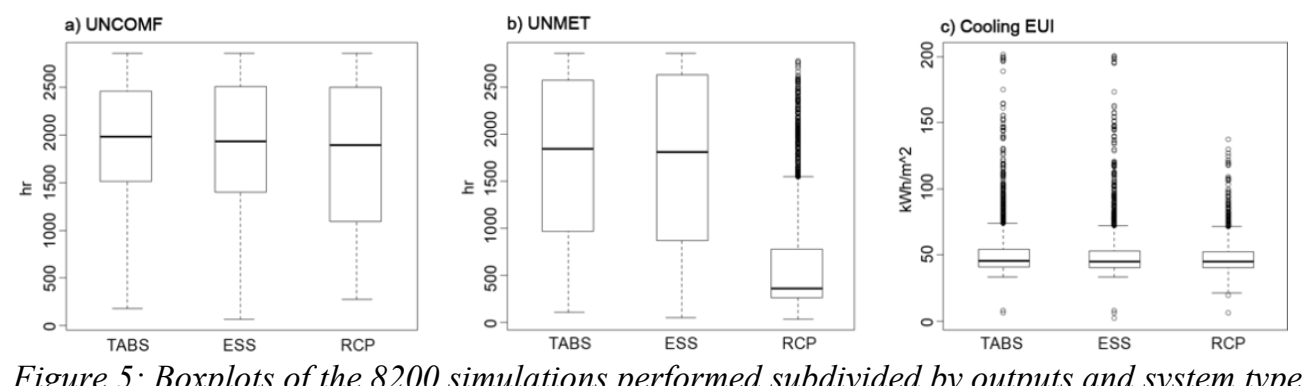

Figure 5: Boxplots of the 8200 simulations performed subdivided by outputs and system types. 

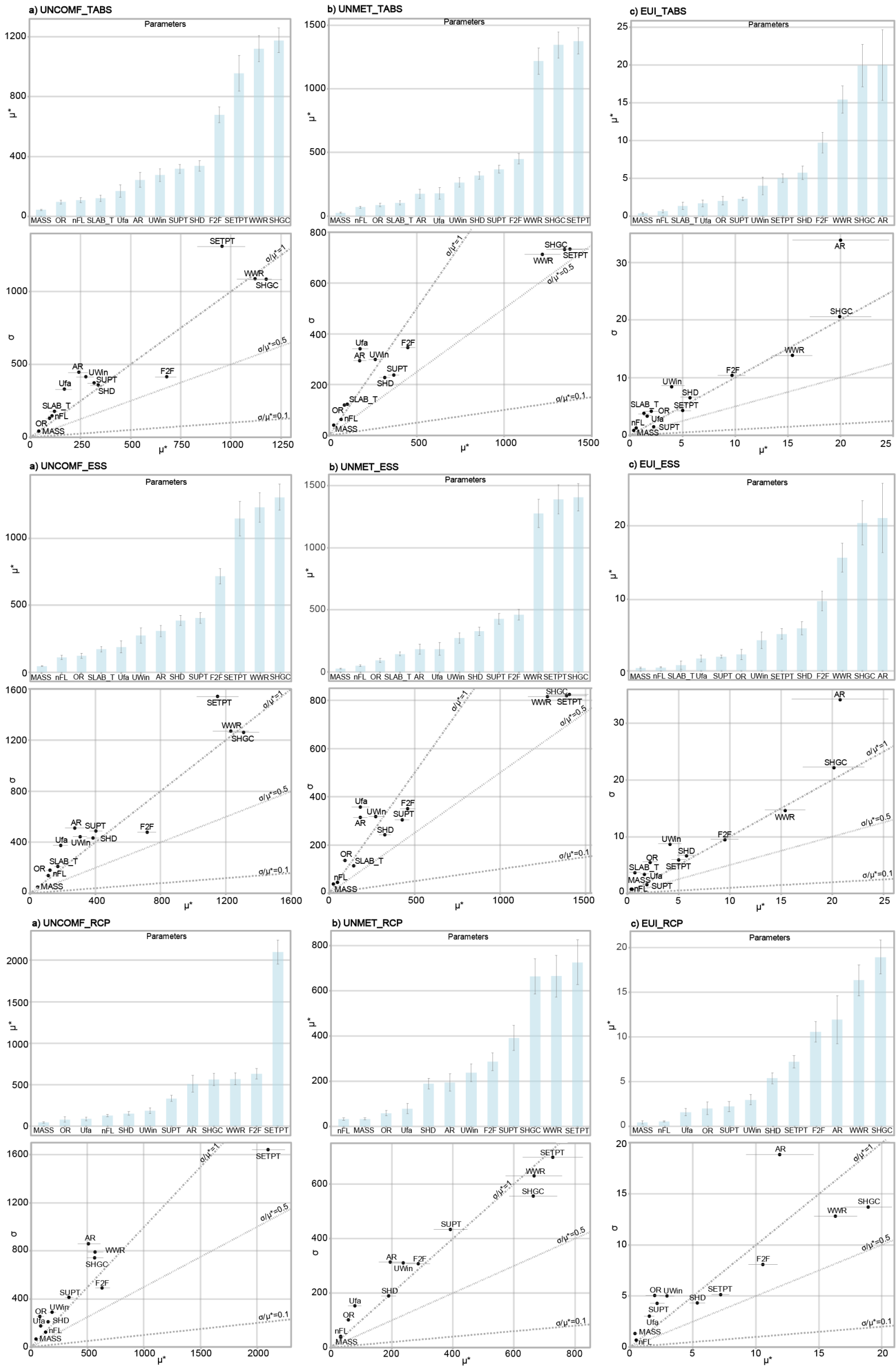

Figure 6: $\mu^{*}$ and $\sigma / \mu^{*}$ on thermal comfort, system operation, and cooling energy consumption for TABS, ESS and RCP. 
When assessing the sensitivity of TABS for unmet setpoint hours, the parameter with the highest $\mu^{*}$ value is the set-point temperature. Additionally, the window solar heat coefficient and the façade window-to-wall ratio play a central role. A second group of parameters which comprises, in descending order, the building floor-tofloor height, the system supply temperature, the façade shades length, the window U-value, the façade U-value and the building aspect ratio have a significant influence while the remaining parameters are negligible. It is notable how the overall sensitivity ranking is similar to the thermal comfort results besides an increased importance of the system supply temperature and the performance of the envelope (U-value). Regarding the higher-order effects, the most influential parameters stay within the almost-monotonic zone as well as building floor-to-floor ratio, system supply temperature and façade shades length from the second influential input group. However, it can be inferred that the façade U-value, the building aspect ratio, and the window U-value might interact between each other and minor parameters, characterized by non-monotonic non-linearities.

The sensitivity of TABS design parameters to cooling EUI highlights the building aspect ratio as having the highest impact, followed by the window solar heat gain coefficient, and the façade window-to-wall ratio. A subsequent group of parameters with lower impact but significant influence includes the building floor-to-floor ratio followed by the façade shades length, the system setpoint temperature, and the window U-value. The remaining parameters can be considered negligible. It is noteworthy pointing out that the system supply temperature and the façade U-value show a much lower influence when considering the cooling EUI output. The $\sigma / \mu^{*}$ ratio scatterplot displays that most of the factors show non-monotonic non-linearities or interactions besides the façade window-to-wall ratio, the system setpoint, and supply temperature (on the verge of the monotonic zone).

\section{ESS results}

Overall, the results for Embedded Surface Systems (ESS) distribution type are in close agreement with the previously analysed TABS. The ranking of the most sensitive parameters, the identification of the negligible factors, the classification of the floor-to-floor height as the fourth most influential input, and the higher-order effects remain unchanged, although with some small impact variations. For this reason, the authors decided to analyse the results in comparison with TABS.

When analysing sensitivity for unmet setpoint hours, the window solar heat coefficient, the set-point temperature and the façade window-to-wall ratio play, in this order, a central role. The indoor uncomfortable hours' bar chart displays the system supply temperature as having a bigger impact than the façade shades length as well as the building aspect ratio on the window U-value. Moreover, the building window-to-wall ratio can be categorized within the factors showing a non-linear influence or interaction with other parameters (system set-point and supply temperature, building aspect ratio, façade U-value and shades length and window U-value) as well as the system set-point temperature when considering the total cooling energy consumption.

\section{RCP results}

The sensitivity results for Radiant Ceiling Panels (RCP) are presented in the following section. The system set point temperature plays alone a major role when considering sensitivity on thermal comfort. The building floor-to-floor height and aspect ratio, the façade windowto-wall ratio and window solar heat coefficient can be ranked within the second group of influential parameters with similar values of importance, including the system set point temperature with a slight lower sensitivity coefficient. The remaining parameters can be classified as negligible. The $\sigma / \mu *$ ratio identifies the system set point temperature as almost-monotonic as well as the building floor-to-floor height from the second group while, the building aspect ratio, the façade window-to-wall ratio, the window solar heat gain coefficient, and the system supply temperature show a non-linear influence or interaction with themselves or other otherwise negligible parameters.

When assessing the sensitivity for unmet setpoint hours, the parameter with the highest $\mu^{*}$ value is the set-point temperature. Additionally, the façade window-to-wall ratio and the window solar heat coefficient ratio play a major role. A subsequent group of parameters which comprises, in descending order, the system supply temperature, the building floor-to-floor height, the window U-value, the building aspect ratio, and the façade shades length have a significant influence while the remaining parameters are negligible. For our test model, regarding the higher-order effects, the most influential parameters stay within the almost-monotonic zone. However, it can be inferred that the all the inputs from the second group and the negligible parameters might interact between each other, characterized by a non-linear behaviour with the outputs.

The total cooling energy consumption ranking chart displays that the window solar heat gain coefficient has the highest impact, followed by the façade window-towall ratio and the building aspect ratio. A subsequent group of factors with lower impact but significant influence includes the building floor-to-floor ratio followed by the system set-point temperature and the façade shades length. The remaining parameters can be considered negligible. The highest-impact parameters and the second group exhibit almost-monotonic behaviours besides the building aspect ratio which is non-linear and/or interacting with other parameters.

\section{Discussions}

Generally, the results indicate that occupant's thermal comfort and system operation are mainly governed by the same 3 input variables (window solar heat gain coefficient, façade window-to-wall ratio, and system setpoint temperature) with almost monotonic behaviours. In addition to these parameters, the building aspect ratio has a higher impact when considering energy performances. The analysis of the results for RCP regarding thermal 
comfort show instead that the system set-point temperature alone plays a dominant role, and the building floor-to floor height is the second most important parameter.

Building aspect ratio, floor-to-floor height, façade shade depth, window U-value, and system supply temperature have a significant impact on performance criteria, mostly showing marked non-monotonic non-linearities or interactions with other factors. The remaining input factors (building massing, number of floors, orientation, slab thickness and façade U-value) can be classified as less important exhibiting a small influence on the results and, in some cases, negligible, mostly characterized by non-monotonic behaviors or interactions between each other or important parameters. None of the factors have an almost linear relationship with the results or a monotonic behavior. It is expected that none of the parameters would significantly affect the results when interacting between each other due to (1) similar $\sigma$ and $\mu^{*}$ values showing a very narrow variability on the percentage of influence (second-group parameters) or (2) notably higher $\mu^{*}$ values assessing marked percentages of contribution (dominant and less important parameters).

Architectural design for building performance is not only a complex interaction of factors, but multi-design goals are involved as well in the decision-making process. Often these design goals can be conflicting; therefore, a deeper understanding of their interactions with design parameters is needed to understand the parameter variability that fits certain criteria. Parallel coordinate plots are presented in Figure 7 to analyse how the parameters are distributed when setting filtered highperforming goals for occupant's thermal comfort, system performance and energy consumption simultaneously. The filtering criteria is based firstly on ASHRAE 90.1 Standard (2016) which requires the number of hours in a year that the HVAC system is not able to maintain the space set-point to be below 300 out of 8760 hours simulated. Secondly, the $5 \%$ best results are filtered from the HVAC energy consumption and occupant's comfort values. Only the simulation results that match the first criteria and remain after being filtered by the second one, are displayed as "high-performance multi-objective". It is notable that overall the variables span is smaller when the parameter has been assessed as dominant by the sensitivity analysis, meaning that a restricted range of values can ensure the desired design goals, while, on the other side, the variability increases when the parameter is considered negligible with multiple design possibilities allowing the same output values.

All 3 radiant typologies require façade window-to-wall ratio and window solar heat gain coefficient values falling below or equal to $57 \%$ and 0.54 , respectively. This indicates the necessity of adopting spectrally selective glazing and suggests the reduction of the façade glazed surfaces. TABS display the lowest window solar heat gain coefficient variability from 0.2 to 0.3 while RCP allow the adoption of 0.2-0.54; ESS instead require values up to 0.4. $\mathrm{RCP}$ are the most flexible when considering the façade window-to-wall ratio with a span of $20-57 \%$ compared to a slightly lower value of up to $51 \%$ for both TABS and ESS. When analysing the system set-point temperature, it is found that, as predicted, high room temperatures from $24.8{ }^{\circ} \mathrm{C}$ to $27{ }^{\circ} \mathrm{C}$ are preferred to achieve the multiobjective goals and help exploiting the potentialities of radiant cooling. This is because the large radiant cooling surfaces reduce the amount of air needed to be moved by convection, therefore allowing people to feel comfortable at a higher air temperature set-point. RCP allow higher temperatures and small operational ranges $\left(25.8-27^{\circ} \mathrm{C}\right)$ than ESS and TABS $\left(24.8-26.6{ }^{\circ} \mathrm{C}\right)$. Floor-to-floor height displays a variability comprised between $2.4 \mathrm{~m}$ and $3.7 \mathrm{~m}$ although the majority of simulation results are equal or below $2.8 \mathrm{~m}$. Lower floor-to-floor heights are an advantage since they facilitate the heat radiation process reducing the distance between the cool surfaces and occupants. RCP allow a floor-to-floor height equal or below $3.3 \mathrm{~m}$, lower than ESS (3.5 m) and TABS $(3.7 \mathrm{~m})$.

\section{Conclusion}

This manuscript presented a Morris sensitivity analysis of 13 passive (building) and active (system) design parameters on 3 building performance metrics (total cooling energy consumption, thermal comfort and system's operation). The simulations were run on 3 different radiant cooling system types (radiant ceiling

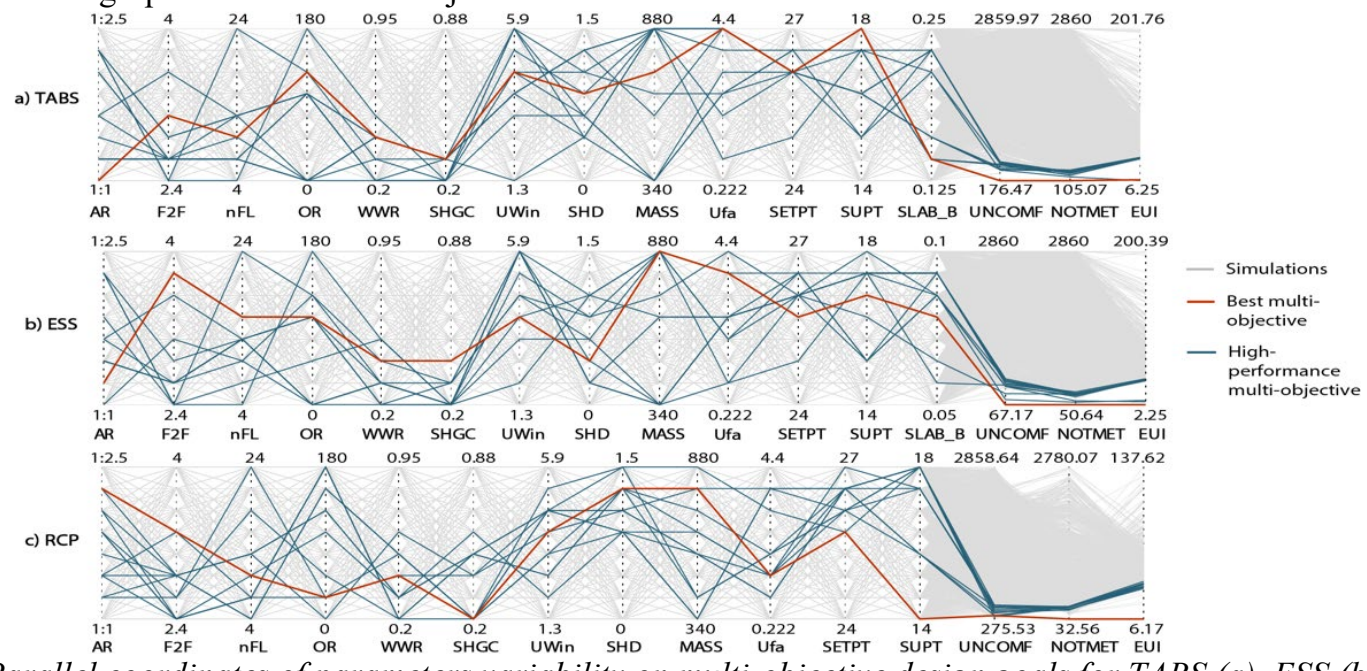

Figure 7: Parallel coordinates of parameters variability on multi-objective design goals for TABS (a), ESS (b), RCP (c). 
panels, embedded surface systems and thermally activated building systems) applied to a parametric office building in the tropical climate of Singapore. The charts provide insights on the identification of variables that have high impacts on the performance indicators, negligible parameters while also underlying their interactions, non-linear effects, and parameter variability related to high-performing multi-objective goals. Based on the feedback obtained from the sensitivity analysis results, the design scenario is simplified and restricted to regions that meet certain design criteria, thus simplifying the design problem and offering guidance in the decisionmaking process. The findings can be readily applied as preliminary design indication in the design of office buildings in the tropics utilizing radiant cooling systems in their conditioning; however, extrapolating the results to other situations may lead to incorrect conclusions. The study can be extended to different climatic locations, building typologies, urban overshadowing conditions and energy systems.

It is found that all 3 system typologies, if coupled with design strategies aimed to reduce the external gains and latent loads, can achieve acceptable thermal comfort levels, system performance and reduced energy consumption. Generally, window solar heat gain coefficient, window-to-wall ratio, and system set-point temperature play a key role to ensure high building's performance and have an almost monotonic behavior with respective values falling below or equal to $54 \%$ and $57 \%$ and high room dry bulb air temperatures between $24.8^{\circ} \mathrm{C}$ and $27^{\circ} \mathrm{C}$. In addition, building aspect ratio, floor-to-floor height, façade shade length, window U-value, and system supply temperature have a significant impact, showing marked non-monotonic non-linearities and/or interactions with other factors. The remaining parameters can be classified as less important and, in some cases, negligible, mostly characterized by non-monotonic behaviors and/or interactions. In other words, architectural design for building's performance is a complex interaction of factors, but through sensitivity analysis, it is possible to assess which are the dominant contributors.

\section{Acknowledgement}

This project is funded by the Singapore National Research Foundation's (NRF) Land and Liveability National Innovation Challenge (L2NIC) under award no. L2NICTDF1-2014-1B.

\section{References}

ASHRAE (2016). ASHRAE Handbook - HVAC Systems and equipment.

ASHRAE (2016). Standard 90.1 - Energy Standard for Buildings Except Low-Rise Residential Buildings.

Babiak, J., Olesen B.W., Petras D. (2009). REHVA Guidebook No 7: Low Temperature Heating and High Temperature Cooling. Belgium.

Campolongo, F., Cariboni, J. and A. Saltelli. (2007). An effective screening design for sensitivity analysis of large models. Environmental Modelling and Software 22, 1509-1518.
Chua, K. J., Chou, S. K., Yang, W. M. and J. Yan (2013). Achieving better energy-efficient air conditioning - A review of technologies and strategies. Applied Energy 104(0), 87-104.

DesignBuilder. (2014). DesignBuilder Software Limited.

Dogan, T. (2013). Archsim Energy Modeling Software.

Duarte, C., Raftery, P. and S. Schiavon (2018). Development of whole building energy models for detailed energy insights of a large office building with green certification rating in Singapore. Energy Technology, 6(1), 84-93.

Garcia Sanchez, D., B. Lacarrière, M. Musy and B. Bourges (2014). Application of sensitivity analysis in building energy simulations: Combining first- and second-order elementary effects methods. Energy and Buildings, 68, Part C(0), 741-750.

Herman, J. and W. Usher (2017). SALib: An open-source Python library for Sensitivity Analysis. Journal of Open Source Software, 2(9), 97.

Jeong, J. W. and Mumma, S. A. (2006). Designing a Dedicated Outdoor Air System with Ceiling Radiant Cooling Panels. ASHRAE Journal 48(10), 56-66.

Karmann, C., Schiavon, S. and F. Bauman (2017). Thermal comfort in buildings using radiant vs. all-air systems: A critical literature review. Building and Environment, 111, 123-131.

Lee, S. E., Schafer, W. and H.S. Majid (2004). Energy Performance Assessment and Classification of Commercial Buildings in Singapore. Report NUS, CTBP. Singapore.

McNeel, R. (2012). Grasshopper - Generative Modeling with Rhino, McNeel North America, Seattle, USA

Menberg, K. C., Heo, Y. and Choudhary, R. (2016). Sensitivity analysis methods for building energy models: Comparing computational costs and extractable information. Energy and Buildings, 133, $433-445$.

Ning, B., Schiavon, S. and F.S. Bauman (2017). A novel classification scheme for design and control of radiant system based on thermal response time. Energy and Buildings 137, 38-45.

Olesen B.W. (2012). Thermo Active Building Systems Using Building Mass To Heat and Cool. ASHRAE Journal 54(2), 44-52.

Saltelli, A., Tarantola, S., Campolongo, F., Ratto, M. (edited by). (2004). Sensitivity Analysis in Practice. John Wiley \& Sons. Chichester (UK).

Talami, R., Karmann, C., Bauman, F., Schiavon, S. and P. Raftery (2017). Recent trends in radiant system technology in North America. Retrieved from https://escholarship.org/uc/item/7pz8p9r6

Tian, W. (2013) A review of sensitivity analysis methods in building energy analysis. Renewable and Sustainable Energy Reviews, 20, 411- 419. 